\title{
Religion and Infant Mortality in the U.S.: A Preliminary Study of Denominational Variations
}

\author{
John P. Bartkowski *, Xiaohe Xu and Ginny E. Garcia \\ Department of Sociology, University of Texas at San Antonio, One UTSA Circle, San Antonio, TX \\ 78249, USA
}

* Author to whom correspondence should be addressed; E-Mail: john.bartkowski@ utsa.edu;

Tel.: +1-210-458-6007.

Received: 12 June 2011; in revised form: 25 June 2011 / Accepted: 5 July 2011 /

Published: 12 July 2011

\begin{abstract}
Prior research has identified a number of antecedents to infant mortality, but has been focused on either structural (demographic) forces or medical (public health) factors, both of which ignore potential cultural influences. Our study introduces a cultural model for explaining variations in infant mortality, one focused on the role of community-level religious factors. A key impetus for our study is well-established religious variations in adult mortality at the community level. Seeking to extend the growing body of research on contextual-level effects of religion, this study examines the impact of religious ecology (i.e., the institutional market share of particular denominational traditions) on county-level infant mortality in the U.S. Analyses of congregational census and Kids Count data reveal that a high prevalence of Catholic and most types of conservative Protestant churches are associated with lower rates of infant mortality when compared with counties that feature fewer Catholic and conservative Protestant congregations. However, communities with a large proportion of Pentecostal churches exhibit significantly higher infant mortality rates. After discussing the implications of these findings, we specify various directions for future research.
\end{abstract}

Keywords: religion; ecology; congregations; infant mortality 


\section{Introduction}

Infant mortality, or the number of infant deaths among children one year-old and younger per 1,000 live births, has long been recognized as a preeminent indicator of the overall health among nations [1,2]. As a cross-cultural and historical marker of social development, the infant mortality rate (or IMR) is a critical component of quality of life indices. Such indices are regularly used by international and domestic governmental agencies, as well as prominent nonprofits concerned about the welfare of children, to rank nations, regions, and states in terms of their social development and their dedication to the well-being of their most vulnerable citizens.

The United States presents a vexing dilemma with respect to infant mortality. Although the U.S. maintains a remarkably high per capita income, its IMRs are disproportionately elevated when compared with other developed nations in the West [1,3]. The infant mortality paradox in the United States continues to generate concern among public health officials and policymakers, many of whom have called for immediate action to reduce the unusually high IMRs in the U.S. [1,4].

Rather alarmingly, the most recent efforts to reduce U.S. IMRs have yielded less than stellar results. As part of its Healthy People 2010 initiative, the U.S. had been aiming to reduce its IMR to 4.5 infant deaths per 1,000 live births [5]. However, most of the first decade of the twenty-first century came and went with little significant change in the U.S. infant mortality rate. The U.S. IMR was 6.89 infant deaths per 1,000 live births in 2000 and had dropped only slightly to 6.86 in 2005, and such stagnant results have not been observed since the 1950s [1]. Quite tellingly, the U.S. has now revised its 2020 objectives to aim for an IMR of 6.0 per 1,000 live births [6].

This study explores the potential effects of religious ecology (that is, community-level denominational market share) on this important social indicator. Why might community-level religiosity be expected to influence the infant mortality rates observed across U.S. counties? Perhaps most notably, the respective market shares of various faith traditions have been shown to influence adult mortality and morbidity patterns across the U.S. [7,8]. Moreover, religious institutions often act as advocates for the well-being of families and children $[9,10]$, such that family ministry programs play a central role in the work of many congregations [11]. Given such prior research, we surmise that religious ecology might influence county-level infant mortality rates in the U.S.

We begin our investigation of this phenomenon with a review of the literature on infant mortality. We then proceed to expand on our rationale for examining how religious ecology might influence infant mortality, arguing for a cultural model to explain IMRs net of structural factors. Next, we describe the population-based sources of data used for the this study, including Kids Count Data, the Glenmary Census of Churches, and select U.S. Census data from the year 2000. After reviewing the results of our investigation, we conclude by considering the implications and limitations of our study while also specifying directions for future research.

\section{Infant Mortality: Summary of Key Antecedents}

Scholars have long examined health disparities across social groups (communities, states, nations) [12-17], and the study of infant mortality has extended this line of research to explain differentials in live birthrates. One avenue of research pursued by demographers studying this issue has explored 
cross-national patterns in infant mortality [3,14,18-19]. In general, these studies have linked high rates of infant mortality to differential access to socioeconomic resources, unsanitary living conditions in developing countries, and restricted health care access $[3,19]$.

Another line of research, more germane to our investigation, has focused on infant mortality differentials within the United States [3,20-21]. Scholars focused on the U.S. have pinpointed three community-level factors associated with inordinately high infant mortality rates. First, and not surprisingly, infant mortality is highly correlated with social inequality, primarily in the form of income and racial stratification [3,22-25]. Concentrated socioeconomic disadvantage has been well documented to create a standard of living that threatens the welfare of families and the well-being of children [26]. Poverty constricts resources that might otherwise be used to promote preventive and, quite significantly in this case, prenatal health care. Within the U.S., infant mortality rates are significantly higher in regions, states, and counties marked by concentrated socioeconomic disadvantage.

In addition, infant mortality varies by locale [24,27]. Although one might expect that rural areas would have higher infant mortality rates due to the lack of a health care infrastructure, metropolitan areas typically exhibit higher rates of infant mortality [27]. This pattern is explained by the concentrated poverty (compromised health facilities, overcrowded housing, and disadvantaged neighborhoods) that marks many urban core areas in the United States [28,29].

Finally, and not unrelated to the foregoing point, health care access has also been linked to infant mortality [3,15,24]. Infant mortality tends to be significantly greater in communities marked by a lower number of hospital beds and physicians per capita. While the links between health care inaccessibility and higher infant mortality rates are again intuitive, there are several possible mechanisms at work here. The provision of preventive prenatal and infant care may be limited by a restricted health care infrastructure. Moreover, when health complications arise during deliveries and postpartum, the ability for successful medical intervention may be hampered in communities lacking a sufficient health care infrastructure.

\section{Religious Ecology and Infant Mortality: Toward a Cultural Model}

What is religiosity? To most Americans and many scholars, religiosity is conceptualized in terms of individual beliefs, convictions, and practices. In this sense, religiosity is commonly defined in terms of a person's beliefs about God or sacred scripture (e.g., images of God as authoritative father vs. loving friend, views about the inerrancy of the Bible), the subjective importance of religion (e.g., religious salience with respect to major life decisions), or an individual's religious practices (e.g., frequency of attendance at weekly worship services, affiliation with a particular denomination). This study is founded on the insight that religion is not solely an individual attribute. It can also function as a group property that influences the climate and quality of life in a community.

Taking a cue from previous research, we use the term "religious ecology" to examine the community-level character and influence of religion [7,30-33]. Religious ecology can be defined in a number different ways. Perhaps the crudest measure of religious ecology is the raw number of congregations (e.g., churches, synagogues, and mosques) or congregants in a given community, adjusted for the population of that community. More sophisticated measures of religious ecology 
examine the "market share" of different types of congregations (e.g., conservative Protestant vs. mainline Protestant vs. Catholic), the prevalence of civically engaged denominations (i.e., a combination of religious groups that are outreach-oriented), and even the presence of faith-based organizations (e.g., religious nonprofit social service agencies) in a community, again with respect to the size of the local population.

The review of prior scholarship featured above demonstrates that, to this point, scholars have utilized either demographic or public health models to explain infant mortality rates. In explaining IMR differentials, demographic models analyze the influence of socioeconomic disadvantage while public health scholars examine gaps in health care provision and access. By pointing to the possible influence of religious congregations on IMRs, we argue here for a cultural model. This cultural model recognizes that religious congregations can influence collective norms whose force is evident in contextual-level outcomes, including health outcomes such as IMRs. It is this insight that drives a great deal of the research on the role of religion in forming moral communities $[31,33]$. Congregations can create a moral ethos in communities that, in a very Durkheimian fashion, yields distinctive social outcomes, including those related to community-level morbidity and mortality patterns.

Beyond the complement that a cultural model might offer to existing approaches, why might community-level religiosity influence infant mortality? Three possible reasons are immediately apparent. First, a great deal of research has demonstrated a clear linkage between religion and health. At an individual level, religious involvement is inversely associated with morbidity and mortality [34-40]. Scholars who have observed this relationship have argued that religious people adhere to healthier lifestyles and practices, experience enhanced social support, and have greater coping resources than their non-religious counterparts [41,42].

The robustness of such findings notwithstanding, survey-based studies on religious differences in individual health are insufficient to warrant an ecological investigation of religion and infant mortality. As demographers are quick to point out, patterns that are observed at one level of analysis (i.e., among individuals) cannot be presumed to operate identically at another (i.e., among whole populations). So, what additional evidence is there that might justify an ecological investigation of religion and infant mortality?

As it turns out, community-level religiosity has been linked to collective mortality patterns (population-based death rates). A recent study by Blanchard and colleagues [7] documented that mortality rates were significantly higher in conservative Protestant communities than in counties dominated by other faith traditions such as mainline Protestantism and Catholicism. Blanchard et al. explained these differences by arguing that the otherworldly, anti-institutional characteristics of conservative Protestantism led to a diminished investment in community infrastructures that promote this-worldly pursuits such as health care. Interestingly, Blanchard and colleagues also performed decomposition analyses to examine mortality rates across communities characterized by different types of conservative Protestant churches, namely, fundamentalist, Pentecostal, evangelical, and other conservative Protestant congregations, with the last of these a residual category for Bible churches not clearly situated in any of the first three subgroups. Blanchard and colleagues found that communities characterized by a larger number of fundamentalist and Pentecostal churches had higher mortality rates than those dominated by their evangelical and other conservative Protestant cousins. They explained these findings by arguing that although evangelical and Bible churches are careful to distinguish 
themselves from the secular world, their desire to attract converts entails maintaining a degree of engagement with the surrounding culture. It is this same secular culture that is more thoroughly shunned by their fundamentalist and Pentecostal counterparts. The especially high rates of mortality evident in Pentecostal communities are likely also a product of the centrality of faith healing within this subgroup and a concomitant distrust of conventional medicine.

Beyond the literatures on religion, health, and mortality, there is also plenty of scholarship underscoring the potential benefits of religion on family life. A primary focus of religious congregations is the provision of services to families, youth, and young children [9-11]. This scholarship underscores the "pro-family" character of religion, with congregations prioritizing family ministry programs over much of the other work they undertake. Moreover, recent research has revealed that strong linkages between religious institutions and families can be beneficial for child development [10]. Taken together, these bodies of research demonstrate that attention needs to be given to the influence of cultural factors, such as religion, on infant mortality.

In light of the foregoing research, and particularly scholarship on denominational market share and adult mortality patterns, we offer the following hypotheses about religious ecology and infant mortality.

H1: Counties with a greater proportion of Catholic and mainline Protestant congregations will exhibit lower infant mortality rates, while those with a greater proportion of conservative Protestant congregations will exhibit significantly higher infant mortality rates.

H2: Among conservative Protestant faith traditions, counties with a greater proportion of fundamentalist and Pentecostal congregations will exhibit significantly higher infant mortality rates, while those with a greater proportion of evangelical and other conservative Protestant congregations will have significantly lower infant mortality rates.

\section{Data and Methods}

The data enlisted in this study are derived from three different sources. Kids Count data were used to generated our dependent variable, namely, infant mortality rates. These rates are available through Kids Count, and were not calculated by the authors. Where possible, year 2000 Kids Count data were used to construct this variable. It is worth noting that Kids Count data provide infant mortality rates for a restricted number of counties, namely, those in which at least one such incident occurred during a given year and those which reported infant mortality data to the federal government. No incident counties and unreported data counties reduce the number of counties available for analysis and thereby compromise these data somewhat. Given clusters of county-level case attrition in the Mountain West, we supplemented infant mortality data for three states (Montana, New Mexico, and Wyoming) through an interpolation method. Missing year 2000 data were interpolated for 56 counties in Montana, 33 counties in New Mexico, and 23 counties in Wyoming by using an average of infant mortality rates from later years (ranging from 2001 through 2005). The combination of available data and interpolated data produced a study region of 1,900 counties. The 112 counties for which data were interpolated do not threaten the validity of our study because these counties constitute a small proportion of our sample (5.89 percent of all counties in our study region). 
Our primary independent variables reflecting county-level religious ecologies, the Glenmary Census of Churches (2000), were retrieved from the Associated Religion Data Archive. Religious denominations in this dataset were coded consistent with the framework developed and utilized in Blanchard et al. [7]. First, major faith traditions were coded into four categories: conservative Protestant, mainline Protestant, Catholic, and other. A series of denominational variables were then created to reflect the number of congregations per 1,000 residents for each denominational family in a county. (Standardizing this measure as the number of denomination-specific congregations per 1,000 county residents creates a comparable baseline of comparison across counties of different sizes.) This coding scheme allows for aggregate analysis of the effects of religious ecology on infant mortality for broad denominational families. In our analysis, each denominational tradition is treated as a continuous variable, such that a specific change (standard deviation increase or decrease) for the denominational variable is associated with a specific change (standard deviation increase or decrease) for the infant mortality rate. When discussing the results of these analyses, we report standardized regression coefficients. Second, to conduct our decomposition analyses, we recoded the conservative Protestant category into four subcategories: fundamentalist, evangelical, Pentecostal, and other conservative Protestant (the last category serving as a residual category that did not fit into the first three categories). The analytical strategy used in this phase of the investigation (that is, unit change in the denominational variable compared with unit change in the infant mortality rate variable) is the same that was used for the major faith traditions. Here again, denominational families are treated as continuous variables.

In light of the previous literature on this subject, we control for three key ecological factors known to influence infant mortality rates. To control for concentrated disadvantage and account for the connection between poverty and race-ethnicity in American society, we include the following covariates (generated through 2000 county-level Census data) in our regression models: percent of population under 18 living below the poverty line, and the percent of the population under age 18 that is black. Given spatial variations in infant mortality, we control for region of the country: Northeast, Midwest, West, and South, with the last of these serving as the reference category. We use ordinary least squares (OLS) regression to conduct these analyses.

\section{Results}

The results of our analyses are reported in Table 1. As can be observed from the table, our study captures nearly two-thirds of the counties in the U.S. Therefore, we use a study sample of 1,900 U.S. counties (from a total of 3,143) to conduct both aggregate analyses (major denominational groupings, Model 1) and decomposition analyses (conservative Protestant subgroups, Model 2).

Recall that Hypothesis 1 predicted lower infant mortality rates for counties with a greater proportion of Catholic and mainline Protestant congregations coupled with higher infant mortality rates for conservative Protestant counties. Our results in Model 1 lend only partial support to this hypothesis. Counties with a high proportion of Catholic congregations have a significantly lower level of infant mortality than counties with fewer Catholic churches. This finding is consistent with our hypothesized effects. However, there is no effect for mainline Protestant counties, which were expected (like Catholic counties) to have a significantly lower infant mortality rate. Moreover, 
although we expected conservative Protestant counties to exhibit a significantly higher infant mortality rate, the findings in Model 1 do not support this hypothesis. The conservative Protestant variable is not statistically significant.

Table 1. Standardized Ordinary Least Squares (OLS) Regression Estimates Predicting Infant Mortality, $\mathrm{n}=1,900$ counties.

\begin{tabular}{lll}
\hline & Model 1 & Model 2 \\
\hline Congregations per 1,000 residents & & \\
Conservative Protestant & -0.052 & \\
$\quad$ Fundamentalist & & $-0.165^{* * *}$ \\
Evangelical & & $-0.109^{*}$ \\
Pentecostal & & $0.232^{* * *}$ \\
Other Conservative Protestant & 0.091 & $-0.091^{*}$ \\
Mainline Protestant & $-0.103^{* *}$ & $-0.082^{*}$ \\
Catholic & $-0.011^{* * *}$ & -0.020 \\
Other & $0.122^{* * *}$ & $0.134^{* * *}$ \\
Adjusted R
\end{tabular}

Note: The following variables are controlled: percent of population under age 18 who are below poverty (2000); percent of population under age 18 that is black (2000); and region (Northeast, Midwest, West, and South). Dependent variable: infant deaths per 1,000 live births.

Next, we turn to our decomposition analyses, which estimate the net effects of our conservative Protestant subgroup variables. Recall that we hypothesized that counties with a greater proportion of fundamentalist and Pentecostal congregations would have significantly higher infant mortality rates, while evangelical and other conservative Protestant counties were expected to exhibit significantly lower rates. These findings, we expected, would mirror religious influences on adult mortality.

As the coefficients in Model 2 of our table indicate, this hypothesis is strongly supported. Based on previous findings related to adult mortality, we expected significant inverse effects for evangelical and other conservative Protestant counties. These expectations were generally met. Counties with a high proportion of evangelical congregations exhibit a significantly lower infant mortality rate, as do counties with a higher proportion of other conservative Protestant congregations. The effects for the Pentecostal variable also support our hypothesis, given that we expected significantly higher infant mortality rates among Pentecostal counties. Our expectations regarding effects for counties with a high proportion of other conservative Protestant congregations were also substantiated. Counties with a large proportion of other conservative Protestant congregations (e.g., Bible churches) exhibit a significantly lower infant mortality rate when compared with counties that have relatively few of these types of congregations. The only finding that runs contrary to our expectations pertains to counties with a high proportion of fundamentalist congregations, which exhibit a significantly lower infant mortality rate. Comparing Models 1 and 2, we observe persistently significant effects for the Catholic variable, which remains significant in the decomposition analyses (Model 2). Contrary to our initial expectations, counties with higher proportions of mainline Protestant churches are more likely to exhibit high infant mortality rates in Model 2, though this relationship was insignificant in Model 1. 


\section{Discussion}

This study examined the effects of religious ecology (that is, community-level denominational market share) on infant mortality. We argued that community-level religiosity may influence infant mortality rates in U.S. counties because (1) adult mortality is affected by the social ecology of religion in communities, and (2) congregations and denominations position themselves as pro-family institutions. Several significant findings emerged. In most of our regression models, higher levels of community religiosity were linked to lower infant mortality rates. However, this pattern was not uniformly observed for all denominational families. In what follows, we summarize and explain our findings. Thereafter, we highlight limitations of our study and identify some promising directions for future research.

Consistent with patterns for adult mortality [7], we found that counties with a higher proportion of Catholic congregations were characterized by lower infant mortality rates. This pattern can be explained by many of the same arguments enlisted by Blanchard and colleagues [7] in which civically engaged denominations can be distinguished from their civically insular counterparts $[31,33,43]$. Catholic congregations are civically minded, externally oriented institutions that place a premium on the creation of community-level care. This argument is consistent with the Catholic theological commitment to "subsidiarity," that is, caring for persons not just as individuals but as groups situated within communities. Contrary to the findings of Blanchard and colleagues, there were inconsistent effects observed for counties characterized by a high proportion of mainline Protestant congregations. Although this pattern is difficult to explain in any definitive fashion, it is possible that the especially strong Catholic commitment to subsidiarity distinguishes Catholic counties from their mainline Protestant counterparts.

Interestingly, the aggregate analyses examining overall conservative Protestant effects on infant mortality did not meet our expectations. Thus, while conservative Protestant counties have produced significantly higher rates of adult mortality, no effects surfaced in such counties where infant mortality is concerned. This non-finding was followed by decomposition analyses that estimated the effects of various conservative Protestant subgroups on infant mortality. These subgroups included fundamentalists, evangelicals, Pentecostals, and other conservative Protestant congregations. Decomposition analyses could reveal subgroup variations that might be masked among conservative Protestants at large. And, indeed, our decomposition analyses did just that.

The decomposition analyses revealed lower rates of infant mortality in counties with higher proportions of fundamentalist, evangelical, and other conservative Protestant congregations. Previous findings on community-level religious variations in adult mortality [7] led us to expect that evangelical and other conservative Protestant counties would exhibit lower infant mortality rates, while fundamentalist and Pentecostal counties would exhibit higher infant mortality rates. Thus, the key difference between infant mortality and adult mortality, where religious effects are concerned, is found in counties that feature a large proportion of fundamentalist churches. Why would three of the four conservative Protestant subgroups (that is, all of them except Pentecostals) create community climates that are less conducive to infant mortality? Conservative Christian churches are not just generic profamily institutions. They are also pronatalist, and are especially vigorous at exhibiting what they argue is a "defense" of those who cannot protect themselves, namely, the young. Nowhere is this position 
more evident than in their opposition to abortion. It is quite possible that the pro-life stance taken by many conservative Protestant congregations make their communities particularly attentive to threats to the welfare of the young. The rhetoric and programs in these congregations may privilege the wellbeing of the young in a way that is quite different from the manner in which adult well-being is treated. In the individualistic worldview of conservative Protestantism, adults may be expected to take care of themselves in a way that children could not be expected to do so.

Why, then, do counties with a higher proportion of Pentecostal congregations run counter to this pattern that is so evident among the three other subgroups of conservative Protestants? One of the key elements of the Pentecostal faith tradition is a commitment to faith healing [44]. It is possible that in such communities, a collective wariness toward medical interventions leads to an ethos in which prenatal or postpartum care is institutionally and normatively deemphasized. Perhaps both preventive care and medical intervention in the face of complications are collectively defined as a demonstrated lack of faith in God. Although more research is clearly needed on this front, the much higher rates of adult mortality (previous research) [7] and infant mortality (our study) in counties with higher proportions of Pentecostal congregations lend credibility to this interpretation.

This study is not without limitations. First, we cannot establish direct causal connections between religious ecology and infant mortality in this study. In a preliminary investigation of this sort, we have included only select control variables. Future research could control for a wider array of factors, such as health care access, to determine if such factors mediate or moderate the relationship between religious ecology and infant mortality. Moreover, in this cross-sectional investigation, we cannot presume the direction of causality. We view it as reasonable to presume that religious ecology exerts an influence on infant mortality, but cannot dismiss arguments about reverse causality without additional data. It is possible that communities with lower rates of infant mortality are more receptive to religious institutions because the faith of their residents is not "tested" in the same way as communities marked by higher infant mortality rates. Consequently, a longitudinal analysis using 2000 and 2010 data presents itself as a promising direction for future research. Such a follow-up investigation would be valuable for introducing more contemporary data, but also for trying to determine possible causal connections between religious ecology and infant mortality. That investigation would require different methods and statistical techniques than we have used here (e.g., controlling for changes in religious ecology over time) and, as such, is beyond the scope of our current investigation.

Second, as mentioned in our methodology section, the dependent variable for this study was drawn from Kids Count data and, therefore, reflects a restricted sample of counties in the U.S. Some of these counties were characterized by no incidents and others simply seemed not to report data on this vital statistic. Therefore, while the findings presented here are the product of rigorous analytical procedures and statistical tests, these data limitations lead us to call for more research on religious variations in infant mortality. Given the fact that our study is predicated on a restricted county sample, the effort undertaken here must be treated as a preliminary investigation into the phenomenon. Additional research is needed with the full universe of U.S. counties to determine if the findings generated with our more restrictive sample of counties hold across all U.S. counties.

Third, as illustrated by our literature review, a good deal of current research on infant mortality adopts a comparative perspective by exploring cross-national patterns and trends. Our study was 
limited inasmuch as it focused on infant mortality in one country, namely, the United States. Additional research is needed to explore the ecological effects of religion on infant mortality across national borders. There is much to gain from broadening the investigative lens with cross-national comparisons, as there may be peculiarities associated with particular traditions in the U.S. context that may not be observed elsewhere in the world. For example, the Catholic penchant for community engagement and its association with lower rates of infant mortality may be due to the minority status and historic marginalization of Catholicism in the United States, a predominantly Protestant country.

Fourth, there are some fruitful alternative means of defining religious ecology that we did not explore here. For example, previous research has demonstrated that a preponderance of civically engaged denominations, as initially operationalized by Tolbert and colleagues [43], often produce salutary community outcomes [31,43]. The influence of these types of denominations on infant mortality is quite worthy of investigation. In addition, infant mortality rates could vary in terms of the religious diversity exhibited in local communities. Because religious competition and commitment may be greater in communities characterized by a high degree of denominational diversity, the use of an index of religious dissimilarity presents an intriguing prospect for further specification of the relationship between religious ecology and infant mortality. Once again, this last avenue of inquiry could be quite fruitfully examined not only with U.S. data, but with international data as well.

These limitations and promising directions for future research notwithstanding, our investigation adds significantly to the literature on infant mortality. To this point, explanations of infant mortality differentials have been dominated by either demographic or public health approaches. Demographers have enlisted a structural model that emphasizes, among other factors, how poverty and concentrated disadvantage contribute to higher infant mortality rates. By contrast, public health approaches utilize a medical model to explain infant mortality. The medical model examines how factors such as health care access (e.g., physicians per capita) may contribute to infant mortality rates. This study represents a first step toward examining a cultural model of infant mortality. Central to this cultural model is the moral ethos that religious institutions can create in communities, and the way in which this ethos can produce real-world effects on population health, in this case, infant mortality. While there is much additional work to be conducted on this topic, our study demonstrates that cultural factors should no longer be ignored in exploring the determinants of infant mortality in the U.S.

\section{Conclusions}

This study revealed that the social ecology of religion (denominational market share) is associated with county-level infant mortality rates. Using data from the year 2000, we found that counties with a high proportion of Catholic churches are significantly more likely to have a low infant mortality rate. This finding is best explained by the emphasis that Catholicism places on creating a vibrant civic infrastructure, particularly one focused on promoting population health and well-being. Although our general measure of conservative Protestant market share did not produce any significant effects in a preliminary model, our follow-up decomposition analyses compared the respective influences of different types of conservative Protestant congregations (fundamentalist vs. evangelical vs. Pentecostal) on county-level infant mortality rates. The decomposition analyses demonstrated that counties with a high proportion of fundamentalist, evangelical, and other conservative Protestant 
congregations (Bible churches) have significantly lower infant mortality rates, while those with a high proportion of Pentecostal churches have significantly higher infant mortality rates. It is quite likely that the pronatalist tendencies of fundamentalism and evangelicalism (advocacy for children and the unborn) contribute to significantly lower infant mortality rates in areas where these churches enjoy a large market share. Pentecostalism presents an interesting deviation from this pattern. We suspect that Pentecostal suspicion of conventional medicine and its reliance instead on faith healing accounts for the higher infant mortality rates in counties with many of these congregations. Our study is, of course, a preliminary investigation of this phenomenon. However, these findings meaningfully extend previous research on religion and health while suggesting future opportunities that are ripe for investigation.

\section{References}

1. MacDorman, M.F.; Mathews, T.J. Recent Trends in Infant Mortality in the United States. U.S. Dept. of Health and Human Services, Centers for Disease Control and Prevention, National Center for Health Statistics: Hyattsville, MD, USA, 2008.

2. World Bank. World Development Indicators. World Bank: Washington, DC, USA, 2011.

3. Pampel, F.; Pillai, V. Patterns and Determinants of Infant Mortality in Developed Nations, 19501975. Demography 1986, 23, 525-542.

4. Cramer, M.E.; Chen, L.; Roberts, S.; Clute, D. Evaluating the Social and Economic Impact of Community-Based Prenatal Care. Public Health Nurs. 2007, 24, 329-336.

5. U.S. Department of Health and Human Services. Healthy People 2010, 2nd ed.; Government Printing Office: Washington, DC, USA, 2000.

6. U.S. Department of Health and Human Services. Developing Healthy People 2020: The Road Ahead; Government Printing Office: Washington, DC, USA, 2009.

7. Blanchard, T.C.; Bartkowski, J.P.; Matthews, T.L.; Kerley, K.R. Faith, Morality, and Mortality: The Ecological Impact of Religion on Population Health. Soc. Forces 2008, 86, 1592-1618.

8. Dwyer, J.W.; Clarke, L.L.; Miller, M.K. The Effect of Religious Concentration and Affiliation on County Cancer Mortality Rates. J. Health Soc. Behav. 1990, 31, 185-202.

9. Bartkowski, J.P. Religious Socialization among American Youth: How Faith Shapes Parents, Children, and Adolescents. In The Sage Handbook of the Sociology of Religion; Beckford, J.A., Demerath, N.J., III, Eds.; Sage: Thousand Oaks, CA, USA. 2007; pp. 511-525.

10. Bartkowski, J.P.; Xu, X.; Levin, M.L. Religion and Child Development: Evidence from the Early Childhood Longitudinal Study. Soc. Sci. Res. 2008, 37, 18-36.

11. Wilcox, W.B.; Chaves, M.; Franz, D. Focused on the Family? Religious Traditions, Family Discourse, and Pastoral Practice. J. Sci. Study Relig. 2004, 43, 491-504.

12. Bird, S.T.; Bauman, K.E. The Relationship between Structural and Health Services Variables and State-Level Infant Mortality in the United States. Am. J. Public Health 1995, 85, 26-29.

13. Diez Roux, A.V. Investigating Neighborhood and Area Effects on Health. Am. J. Public Health 2001, 91, 1783-1789.

14. Frisbie, W.P. Infant Mortality. In Handbook of Population, Poston, D.L.; Micklin, M. Kluwer Academic/Plenum: New York, NY, USA, 2005; pp. 251-282. 
15. Gortmaker, S.L.; Wise, P.H. The First Injustice: Socioeconomic Disparities, Health Services Technology, and Infant Mortality. Annu. Rev. Sociol. 1997, 23, 147-170.

16. Hummer, R.A. Black-White Differences in Health and Mortality: A Review and Conceptual Model. Sociol. Quart. 1996, 37, 105-125.

17. Leclere, F.B.; Rogers, R.G.; Peters, K. Neighborhood Social Context and Racial Differences in Women's Heart Disease Mortality. J. Health Soc. Behav. 1998, 39, 91-107.

18. Conley, D.; Springer, K.W. Welfare State and Infant Mortality. Am. J. Sociol. 2001, 107, 768-807.

19. Kim, K; Moody, P.M. More Resources Better Health? A Cross-National Perspective. Soc. Sci. Med. 1992, 34, 837-842.

20. Dorsten, L.E. Direct and Indirect Effects on Infant Mortality in a High-Fertility U.S. Population. Popul. Res. Policy Rev. 1994, 13, 31-48.

21. Eberstein, I.W. Demographic Research on Infant Mortality. Sociol. Forum 1989, 4, 409-422.

22. Guest, A.M.; Almgren, G.; Hussey, J.M. The Ecology of Race and Socioeconomic Distress: Infant and Working-Age Mortality in Chicago. Demography 1998, 35, 23-34.

23. Macinko, J.A.; Shi, L; Starfield, B. Wage Inequality, the Health System, and Infant Mortality in Wealthy Industrialized Countries, 1970-1996. Soc. Sci. Med. 2004, 58, $279-292$.

24. Matteson, D.W.; Burr, J.A.; Marshall, J.R. Infant Mortality: A Multi-Level Analysis of Individual and Community Risk Factors. Soc. Sci. Med. 1998, 47, 1841-1854.

25. Muhuri, P.K.; MacDorman, M.F.; Ezzati-Rice, T.M. Racial Differences in Leading Causes of Infant Death in the United States. Pediatr. Perinat. Ep. 2004, 18, 51-60.

26. Alexander, G.R.; Wingate, M.S.; Bader, D.; Kogan, M.D. 2008. The Increasing Racial Disparity in Infant Mortality Rates: Composition and Contributors to Recent US Trends. Am. J. Obstet. Gynecol. 2004, 198, e1-e9.

27. Clarke, L.L.; Farmer, F.L.; Miller, M.K. Structural Determinants of Infant Mortality in Metropolitan and Nonmetropolitan America. Rural. Sociol. 1994, 59, 84-99.

28. Morenoff, J.D. Neighborhood Mechanisms and the Spatial Dynamics of Birth Weight. Am. J. Sociol. 2003, 108, 976-1017.

29. Sampson, R.J. The Neighborhood Context of Well-Being. Perspect. Biol. Med. 2003, 46, S53-S64.

30. Bartkowski, J.P.; Howell, F.M.; Lai, S. Spatial Variations in Southern Church Burnings: An Ecological Study of Victimized Communities. Rural. Sociol. 2002, 67, 578-602.

31. Lee, M.R.; Bartkowski, J.P. Love Thy Neighbor? Moral Communities, Civic Engagement, and Juvenile Homicide in Rural Areas. Soc. Forces 2004, 82, 1001-1035.

32. Greenberg, A. The Church and the Revitalization of Politics and Community. Polit. Sci. Q. 2000, 115, 377-394.

33. Lee, M.R.; Bartkowski, J.P. Civic Participation, Regional Subcultures, and Violence: The Differential Effects of Secular and Religious Participation on Adult and Juvenile Homicide. Homicide Stud. 2003, 8, 5-39.

34. Dupre, M.E.; Franzese, A.T.; Parrado, E.A. Religious Attendance and Mortality: Implications for the Black-White Mortality Crossover. Demography 2006, 43, 141-164. 
35. Huijts, T.; Kraaykamp, G. Religious Involvement, Religious Context, and Self-Assessed Health in Europe. J. Health Soc. Behav. 2011, 52, 91-106.

36. Hummer, R.A.; Ellison, C.G; Rogers, R.G.; Moulton, B.E.; Romero, R.R. Religious Involvement and Adult Mortality in the United States: Review and Perspective. South. Med. J. 2004, 97, 1223-1230.

37. Jarvis, G.K.; Northcott, H.C. Religion and Differences in Morbidity and Mortality. Soc. Sci. Med. 1987, 25, 813-824.

38. Musick, M.A.; House, J.S.; Williams, D.R. Attendance at Religious Services and Mortality in a National Sample. J. Health Soc. Behav. 2004, 45, 198-213.

39. Rogers, R.G.; Everett, B.G.; Saint Onge, J.M.; Krueger, P.M. Social, Behavioral, and Biological Factors, and Sex Differences in Mortality. Demography 2010, 47, 555-578.

40. Sullivan, A.R. Mortality Differentials and Religion in the United States: Religious Affiliation and Attendance. J. Sci. Stud. Relig. 2010, 49, 740-753.

41. Benjamins, M.R.; Ellison, C.G; Krause, N.M; Marcum, J.P. Religion and Preventive Service Use: Do Congregational Support and Religious Beliefs Explain the Relationship between Attendance and Utilization? J. Behav. Med. 2011, in press.

42. Ellison, C.G.; Levin, J.S. The Religion-Health Connection: Evidence, Theory, and Future Directions. Health Educ. Behav. 1998, 25, 700-720.

43. Tolbert, C.M.; Lyson, T.A.; Irwin, M.D. Local Capitalism, Civic Engagement, and Socioeconomic Well-Being. Soc. Forces 1998, 77, 401-427.

44. Brown, C.G., Ed. Global Pentecostalism and Charismatic Healing; Oxford University Press: New York, NY, USA, 2011.

(C) 2011 by the authors; licensee MDPI, Basel, Switzerland. This article is an open access article distributed under the terms and conditions of the Creative Commons Attribution license (http://creativecommons.org/licenses/by/3.0/). 